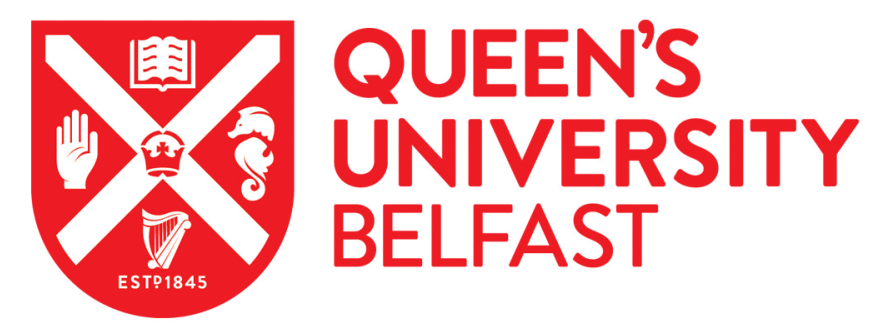

\title{
When innovation fails: An institutional perspective of the (non)adoption of boundary spanning IT innovation
}

Bunduchi, R., Smart, A., Charles, K., McKee, L., \& Azuara-Blanco, A. (2015). When innovation fails: An institutional perspective of the (non)adoption of boundary spanning IT innovation. Information and Management, 52(5). https://doi.org/10.1016/j.im.2015.04.001

\section{Published in:}

Information and Management

\section{Document Version:}

Peer reviewed version

Queen's University Belfast - Research Portal:

Link to publication record in Queen's University Belfast Research Portal

\section{Publisher rights}

(c) 2015, Elsevier. Licensed under the Creative Commons Attribution-NonCommercial-NoDerivatives 4.0 International

http://creativecommons.org/licenses/by-nc-nd/4.0/which permits distribution and reproduction for non-commercial purposes, provided the author and source are cited.

\section{General rights}

Copyright for the publications made accessible via the Queen's University Belfast Research Portal is retained by the author(s) and / or other copyright owners and it is a condition of accessing these publications that users recognise and abide by the legal requirements associated with these rights.

Take down policy

The Research Portal is Queen's institutional repository that provides access to Queen's research output. Every effort has been made to ensure that content in the Research Portal does not infringe any person's rights, or applicable UK laws. If you discover content in the Research Portal that you believe breaches copyright or violates any law, please contact openaccess@qub.ac.uk. 


\title{
When innovation fails: An institutional perspective of the
}

\section{(non)adoption of boundary spanning IT innovation}

\author{
Raluca Bunduchi* \\ Corresponding author \\ University of Aberdeen Business School, Edward Wright Building, Dunbar Street, AB24 3QYI \\ Present address: University of Edinburgh Business School, 29 Buccleuch Place, Edinburgh, EH8 9JS, tel: 0131651 \\ 5544, email: raluca.bunduchi@ed.ac.uk \\ Alison Smart \\ University of Aberdeen Business School, Edward Wright Building, Dunbar Street, AB24 3QYI \\ Present address: Adam Smith Business School, University of Glasgow, Main Building, Glasgow, G12 8QQ, tel: \\ 01413304240, email: alison.smart@glasgow.ac.uk \\ Kathryn Charles \\ Health Services Research Unit, University of Aberdeen, Health Sciences Building, Foresterhill, Aberdeen, AB25 2ZD \\ Lorna McKee \\ Health Services Research Unit, University of Aberdeen, Health Sciences Building, Foresterhill, Aberdeen, AB25 \\ 2ZD , tel: 01224438143, email: I.mckee@adbn.ac.uk \\ Augusto Azuara-Blanco \\ The Eye Clinic, Aberdeen Royal Infirmary, Foresterhill, Aberdeen, AB25 2ZD \\ Present address: School of Medicine, Dentistry and Biomedical Sciences, Queen's University Belfast, Health \\ Sciences Building, 97 Lisburn Road, Belfast, BT9 7BL, tel:02890632507, email: a.azuara-blanco@qub.ac.uk
}

\begin{abstract}
We combine the concepts of legitimacy, institutional (mis)alignments, strategic responses and organizing visions to develop a conceptual framework to analyse the adoption of innovations that span organisational fields. We apply the framework to examine a telehealth innovation connecting a public sector hospital-based eye clinic with private sector optometry practices. We find that while compromise strategies were successful in encouraging adoption within each field, the innovation ultimately failed as fields developed different organising visions which could not be reconciled. The findings suggest that institutional misalignments within and between fields interact to amplify their overall effect on the adoption of hybrid innovations.
\end{abstract}




\section{Keywords}

IT innovation adoption; hybrid innovation; institutional misalignments; strategic responses; organizing vision;

\section{Introduction}

The decision to adopt IT innovations, as well as the success of adoption depends on the alignment between the innovation and institutional characteristics such as mandates from powerful organizations, professional norms, and established ways of working that are prevalent within the adopting organisational fields (e.g. Chatterjee et al., 2002; Liu et al., 2008; Teo et al., 2003; for a review see Mignerat and Rivard, 2009). However, as environments become more complex and contested, organizations increasingly experience conflicting institutional demands (Pache and Santos, 2010). Conflicting institutional demands are important as they call into question the ability of innovator actors to align an innovation successfully with the range of diverse and inconsistent institutional logics that characterise adopting organizational fields (Currie and Guah, 2007). Misalignments between conflicting demands become an even bigger challenge when adoption cuts across different organizational fields characterised by diverse institutional logics. Despite the increased prevalence of such misaligned and contested environments, there has been little systematic effort in IT innovation research to study the role of institutional misalignments, particularly where the adoption of the innovation happens across different organizational fields. Nor has the role that such misalignments play in influencing the adoption of IT innovations at organizational level been investigated. Nevertheless, the extent of misalignments between different institutional logics within the environment in which innovations are introduced plays a critical role in shaping their adoption (see Currie and Guah, 2007). The goal of this paper is to develop an understanding of the nature of these misalignments and how they influence the adoption of IT innovations. 
We build upon existing institutional research on IT adoption to examine the influence of institutional misalignments on the adoption of IT innovations spanning different organizational fields (which we term "boundary spanning innovations"). We argue that these kinds of boundary spanning innovations have a hybrid nature, similar to the hybrid organization concept in institutional research (see Battilana and Dorado, 2010) in that innovation adoption requires a combination of diverse institutional logics. The adoption of boundary spanning innovations necessitates collaboration between adopting organizations in different organizational fields characterised by different norms, rules and procedures. Thus, to be successful, boundary spanning innovations need to strike a balance between various institutional expectations and demands that characterise the different adopting organizational fields. Our first research question is thus:

RQ1: What are the institutional factors that influence the adoption of boundary spanning IT innovations by individual organizations?

Within the information systems literature there is some evidence that competing institutional demands influence IT innovation adoption within particular organizational fields (see for example Currie and Guah's 2007 study on the evolution of a UK-wide healthcare IT programme). Such studies have, however, examined tensions within, rather than between, organizational fields, and have often focused at the field level, thus failing to explain variations in adoption at organizational level. We have found no detailed research examining the role played by misalignments between institutional norms in shaping the organizational adoption of IT innovations spanning different organizational fields. Yet, we argue, these misalignments are more intense in the case of boundary spanning IT innovations. Our next research questions are thus:

RQ2: How do institutional misalignments arise within (RQ2a) and between (RQ2b) organizational fields involved in the adoption of boundary spanning innovations? and; 
RQ3: How do institutional misalignments within (RQ3a) and between (RQ3b) organizational fields influence the adoption of boundary spanning innovations within individual organizations?

We focus here on the adoption of a telehealth system to support the provision of glaucoma care in one Health Board in Scotland. Telehealth has been defined as ' $[t]$ he delivery of healthcare services, where distance is a critical factor, by all healthcare professionals using information and communication technologies for the exchange of valid information for diagnosis, treatment and prevention of disease and injuries, research and evaluation, and for the continuing education of healthcare providers, all in the interests of advancing the health of individuals and their communities" (WHO, 2010 p. 9). The telehealth innovation under study involved privately owned optometry practices carrying out routine checks for some glaucoma patients, and sending the results of these checks to a consultant in a hospital-based Eye Clinic. The hospital was part of the publicly owned UK National Health Service (NHS). The innovation thus spanned the public sector Eye Clinic and privately owned optometry practices. Drawing from a rich, in depth single case study, this paper develops a conceptual framework to examine the mechanisms that lead to the emergence of institutional misalignments, and the outcome that these misalignments have on the adoption of boundary spanning innovation.

\section{Literature Review}

\section{New-institutional theory: legitimacy, institutional pressures and response strategies}

Institutional theory argues that organizations operate within fields that are characterised by a shared understanding of appropriate organizational forms and behaviours (DiMaggio and Powell, 1983). The need for organizations to gain legitimacy in order to increase their probability of survival within their specific environment creates pressures for organizations to conform to these institutional expectations, even if these expectations have little to do with rational norms of efficiency. DiMaggio and Powell (1983) identified three types of institutional pressures: coercive, 
normative, and mimetic. Coercive pressures result from formal and informal pressures from powerful organizations, and from embedded societal cultural expectations; mimetic pressures arise in conditions of high uncertainty and may cause an organization to imitate others that are seen as successful in the field; normative pressures manifest themselves through professionalization, generally through the relational networks that span organizations (DiMaggio and Powell, 1983; Scott, 1987).

An organization has legitimacy within its organizational field when its actions are perceived as "desirable, proper or appropriate" within its particular environment (Suchman, 1995, pg. 574). Organizational legitimacy can thus be understood as the social acceptance of organizational practices (Scherer et al., 2013). Institutional research distinguishes between different forms of organizational legitimacy. We follow Ruef and Scott (1998) who, drawing from a study of innovation in healthcare, identified two forms of legitimacy within organizations: technical and managerial. Technical legitimacy considers the core technology, including normative support for staff qualifications, training programmes, work procedures and quality assurance mechanisms. Managerial legitimacy focuses on organizational mechanisms, including normative support for personnel management, accounting practices, and rules of conduct for administrative staff (Ruef and Scott, 1998).

To gain legitimacy, organizations can choose between a range of institutional responses to the institutional pressures within their environment (e.g. Schuman, 1995, Zimmerman and Zeitz, 2002). Here we follow Oliver (1991), who identified five strategies to maintain, repair or gain legitimacy: acquiescence, compromise, avoidance, defiance and manipulation. Acquiescence is an organization's unqualified conformity to external pressures; compromise refers to an organization's attempts to balance, pacify or bargain with external constituents to match conflicting institutional expectations; avoidance refers to an organization's efforts to circumvent the need to conform to external pressures; defying involves the rejection of institutional norms: while manipulation is aimed at actively changing the content of the institutional expectations or the sources through which these expectations are exerted (Oliver, 
1991). The core framework proposed by the institutional theory is depicted in Figure 1.

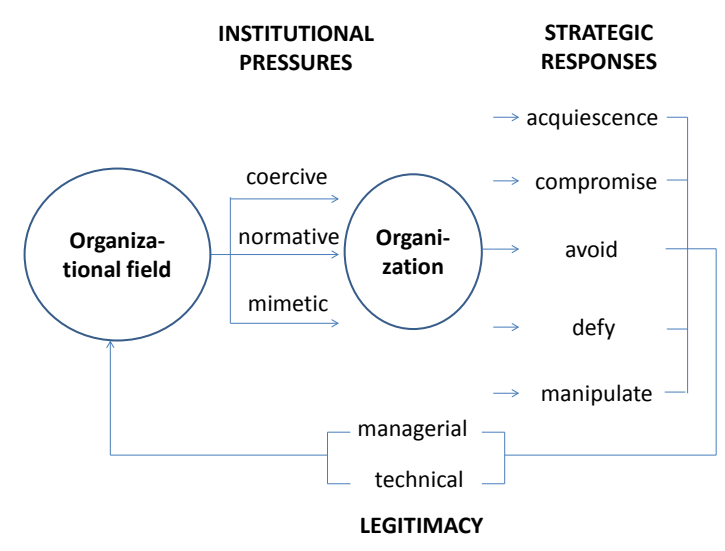

Figure 1: Institutional theory framework

Institutional literature in general, and information systems research in particular, has focused on acquiescence, and little effort has been made to explore the other strategic responses to institutional pressures (Mignerat and Rivard, 2009). There is, however, growing evidence that organizations employ other types of strategic responses in response to conflicting institutional demands (Pache and Santos, 2010; Scherer et al., 2013) and that these responses vary over time (Standing et al., 2009).

\section{Institutional theory and IT innovation adoption}

An increasing body of literature examines IT innovation adoption from an institutional perspective (see Mignerat and Rivard, 2009). To answer our research questions, this study draws from three different streams of institutional IT research (see Figure 2). 

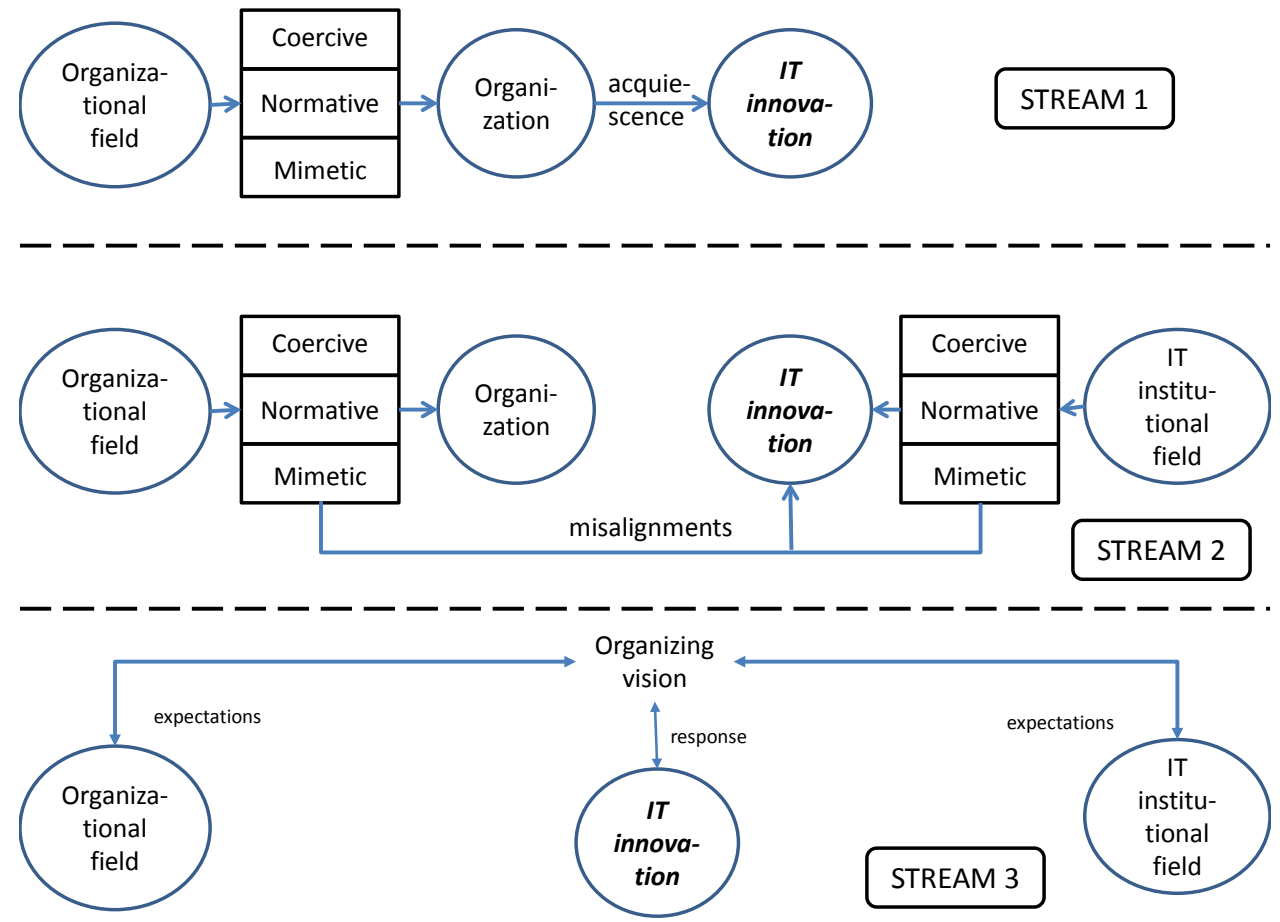

Figure 2: Different streams of institutional research on IT adoption

STREAM 1: A recent review found that most IT institutional research (68\%) examined the influence of institutional pressures at the different stages of IT adoption in organizations (see Figure 2) (Mignerat and Rivard, 2009). Varying combinations of institutional pressures have been found to influence all stages of adoption, ranging from the intention to adopt to assimilation, across different types of IT innovation, ranging from EDI to grid computing (see Table 1). Most studies have focussed on acquiescence strategy, assuming that the only possible response to institutional pressures is conformity (see for instance Gosian, 2004). In one of the few exceptions in the information systems literature, Standing et al. (2009) showed that, in engaging with an IT innovation, organizations adopted a variety of strategic responses, ranging over time from conformity to non-conformity.

\begin{tabular}{|l|l|}
\hline Stage of adoption & Type of IT innovation (authors) \\
\hline Intention to adopt & Electronic Data Interchange (Teo et al., 2003); \\
& B2B electronic market places (Son and Benbasat, 2007); \\
& IT facilitated virtualisation (Liu et al., 2008); \\
& RFID (Tsai et al., 2013); \\
& Grid computing (Messerschmidt and Hinz, 2013); \\
\hline
\end{tabular}




\begin{tabular}{|c|c|}
\hline & $\begin{array}{l}\text { Internet enabled supply chain management systems (Liu et al., } \\
\text { 2010) }\end{array}$ \\
\hline Adoption & $\begin{array}{l}\text { Purchasing and sales e-business systems (Hertwig, 2012); } \\
\text { Enterprise resource planning (ERP) (Benders et al., 2006) }\end{array}$ \\
\hline Implementation & $\begin{array}{l}\text { Electronic human resource management practices (Hiekkila, } \\
\text { 2013); } \\
\text { ERP (Benders et al., 2006) }\end{array}$ \\
\hline Assimilation & $\begin{array}{l}\text { Web technologies (Chatterjee et al., 2002); } \\
\text { Internet-based inter-organizational systems (Sodero et al., } \\
\text { 2013); } \\
\text { ERP (Liang et al., 2007) }\end{array}$ \\
\hline
\end{tabular}

Table 1. Studies of conforming to institutional pressures and IT adoption stages

STREAM 2: Research has also examined, although to a more limited extent, the role of institutional misalignments in IT adoption (see Figure 2). In particular, research has considered the tensions between (i) institutional arrangements in one organizational field within which innovation happens; and (ii) the institutional logic embodied within the IT innovation itself. For example, misalignments between institutional arrangements on one hand and a medical innovation (Cho and Mathiassen, 2007; Jensen et al., 2009), or a nationwide IT programme (Currie and Guah, 2007) on the other, were found to explain the lack of adoption within healthcare settings. Similarly, it has been suggested that mismatches between the institutional logic embodied within a new information system and the dominant institutional logic within the adopting organization create resistance to the implementation of IT innovations at an organizational level (Gosain, 2004).

STREAM 3: Organizational adoption of IT innovations has also been explained by examining the perceptions and responses of organizational members to the organizing vision associated with an IT innovation (see Figure 2) (Marsan et al., 2012; Sawnson and Ramiller, 2004). An organizing vision embodies the early efforts of a diverse community of prospective adopters, technology vendors, consultant firms and industry experts to make sense of the innovation as an organizational opportunity (Swanson and Ramiller, 1997). A compelling organizing vision can support innovation adoption and diffusion by reconciling different interpretations of the IT innovation, legitimising the innovation within the adopting organizational fields, and organizing 
and mobilising resources to support the innovation (Swanson and Ramiller, 1997). In contrast, when the innovation is characterised by mismatching interpretations and mixed messages within a community, the ability of users to make sense of the innovation is hampered. This situation produces contradictory expectations within the community and obstructs the formation of a coherent organizing vision, thus leading to the innovation failing within an organizational field (Currie, 2004).

Existing research has demonstrated the need for alignment between the innovation and the institutional demands prevalent within the adoption field (RQ1), thus significantly advancing our understanding of the role of institutions for innovation adoption. This understanding is however not yet complete. First, until recently most IT research assumed a cohesive set of institutional norms to which adopting organizations conform. It also assumed that these norms align to influence IT adoption (see Chatterjee et al., 2002; Teo et al., 2003; Son and Bensabat, 2007) (STREAM 1). There is, however, mounting evidence that organizations are subject to competing institutional demands within their organizational fields (Reay and Hinings, 2009; Scherer et al., 2013), and that these conflicting demands influence IT innovation adoption (Butler, 2003) and diffusion (Currie and Guah, 2007). However, existing information systems research has primarily examined one category of conflicts misalignments between the organizational field and the institutional demands embodied within the IT artefact (see Gosian, 2004; Jensen et al., 2009) (STREAM 2). In contrast, little attention has been paid to the institutional conflicts inherent within the organizational field itself. As environments become more complex and fragmented it is likely that organizations will be increasingly subjected to conflicting institutional demands (Pache and Santos, 2010) that will shape their approach to IT innovation. How these conflicting institutional demands arise (RQ2a) and shape the adoption of innovation within a particular organizational field (RQ3a) is not yet clear (see Gap 1 in Figure 3). 


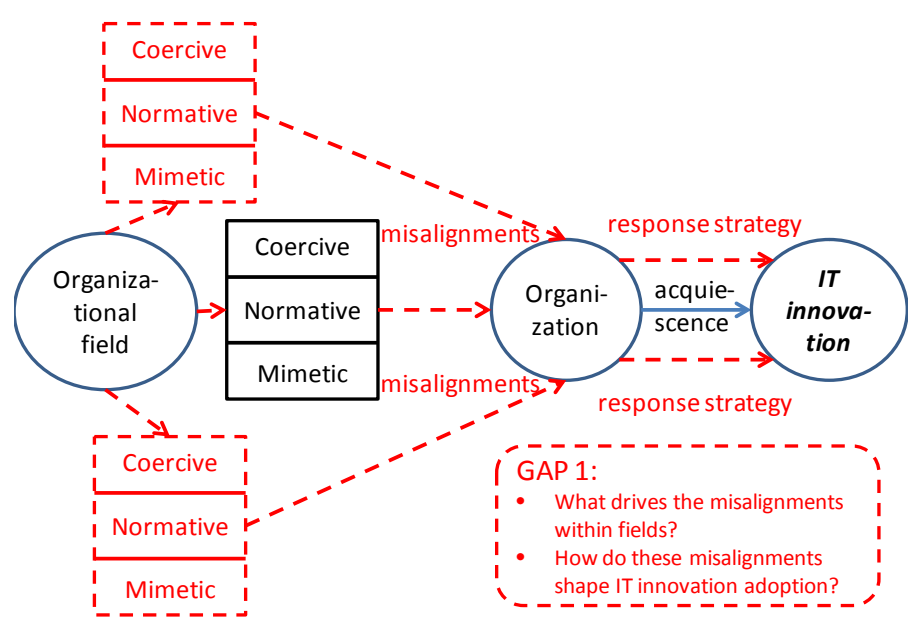

Figure 3. Gap 1: Conflicting institutional factors within organizational fields and different responses

In answering these questions, this study draws from the concepts of managerial and technical legitimacy (Ruef and Scott, 1998), and response strategies to institutional pressures (Oliver, 1991). IT institutional research does not generally differentiate between types of legitimacy within adopting organizations. Managerial and technical legitimacy are, however, governed by different, and often conflicting, societal values (Ruef and Scott, 1998). Misalignments between technical and managerial norms are particularly evident in professional organizations that are characterised by broadly defined groups where these groups are subject to different values and expectations (Ferlie et al., 2005). For example, in a healthcare setting doctors (professionals) and administrators (managers) will have different values and expectations (Willcocks, 2004), as will musicians and administrators in symphony orchestras (Glynn, 2000). The professional groups seek technical legitimacy, focusing on norms of professional excellence (quality of patient care and specialism training for doctors and artistic excellence for musicians). The managerial groups seek managerial legitimacy through norms such as economic efficiency and cost-containment (Glynn, 2000; Ruef and Scott, 1998). Consequently, tensions between the 'technical' and 'managerial' institutional pressures may lead to institutional misalignment. Organisations can respond to these institutional misalignments in different ways. For example efforts can be made to balance the competing technical and managerial pressures. Alternatively, organisations might attempt to persuade the different stakeholders to 
alter their institutional demands, or they might even avoid compliance all together (Oliver, 1991). Different responses to institutional misalignments may influence their decision to adopt an innovation, as well as the success of adoption.

With few exceptions, misalignments between technical and managerial norms are not considered in IT research. For example, institutional misalignments within UK healthcare were identified by Currie and Guah (2007) and were found to both fuel and inhibit the diffusion of a nationwide IT innovation. The conflicts within the healthcare field were explained largely based on the fragmentation of the organizational field, which was characterised by the conflict between public and private sector ethoses (see also Reay and Hinings, 2009). This fragmentation made it difficult to reach a consensus between the various IT programme stakeholders and explained the lack of adoption (Currie and Guah, 2007). Building upon these findings on the diffusion of innovation at field level, our research considers individual organizations, and examines the mechanisms through which institutional misalignments within particular organizational fields emerge (RQ2a) and shape IT adoption within individual organizations (RQ3a).

Second, existing IT institutional research focuses on IT innovation adoption within a single organizational field. However, as early as the 1980 s researchers pointed out that modern organizations frequently operate in multiple fields (Scott, 1987). While cross-field institutional demands might be less evident for single-field IT innovations, they are a defining characteristic of the adoption of boundary spanning innovations, whose development and adoption takes place in multiple fields, subject to varying institutional norms. How these conflicting institutional demands arise (RQ2b) and influence the adoption of innovation across different organizational fields (RQ3b) is not clear (see Figure 4) and is the second research gap addressed by this research. 


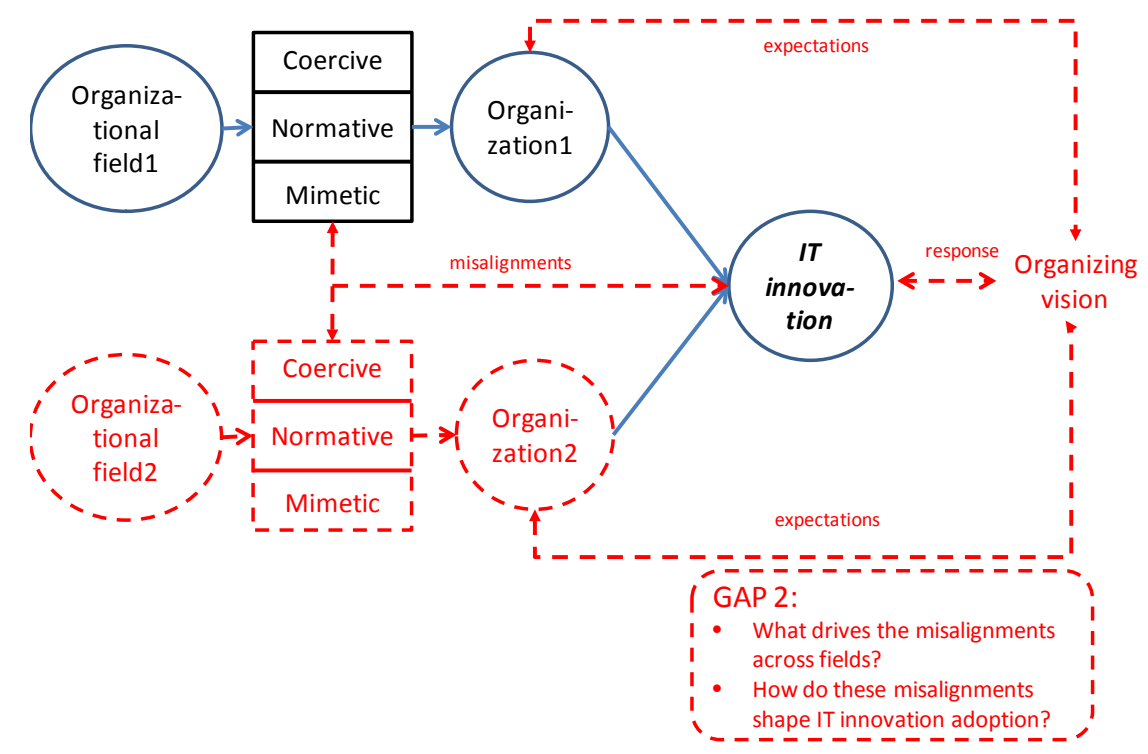

Figure 4. Gap 2: Conflicting institutional factors across organizational fields and different organizing visions

In examining these questions, this study draws upon the concept of 'organizing vision' (Swanson and Ramiller, 1997). Faced with an IT innovation, organizations form expectations about the innovation. These expectations provide a framework that enables organizational members to make sense of the innovation; it guides their perceptions and decision-making about, and actions in dealing with, the innovation. Innovation adoption by individual organizations does not, however, take place in isolation. Organizations are part of a broader community of actors who are interested in the development and adoption of the innovation. Other members of this broader community might develop their own conceptual frameworks. As community members interact, they bring together their individual conceptual frameworks, which are adapted, refashioned and altered to form a vision for organizing the innovation in a way that embeds and utilises the innovation within existing organizational structures and processes (Swanson and Ramiller, 1997).

The concept of organizing vision was originally developed to explain the institutionalisation of IT innovations at field level, and has recently been applied to examine adoption at an inter-organizational level (Lyytinen and Damsgaard, 2011). Here we adapt the concept of organizing vision to explain adoption at organizational 
level. The way in which community members negotiate their individual conceptual frameworks between themselves, and/or in relation to the emerging organizing vision, may influence their decision on whether or not to engage in an innovation. For example Marsan et al. (2012) found that when specific organizational members held positive perceptions of the organizing vision of an innovation, the organization was more likely to favour adoption. Moreover, competing organizing visions may develop between different organizational fields: in their attempt to make sense of a boundary spanning innovation, adopting organizations may form conflicting understandings of the application of the innovation within their particular fields. For example, in the context of technology development, conflicting institutional demands across institutional fields were found to lead to different expectations within the standardisation community about the organization of standardisation bodies (Bunduchi et al., 2008). The way in which potential adopters are able to resolve the conflicts between their particular expectations for the innovation may explain the outcome of the innovation. For examples, for an organizational "boundary spanning" innovation, Batillana and Dorado (2010) found that the success of a new hybrid form of organization depended on the ability of the organization to balance the different institutional logics. Building upon this argument, our study identified the drivers for the emergence of institutional misalignments across different organizational fields involved in IT adoption (RQ2b), and their role in shaping the adoption of boundary spanning IT innovations (RQ3b).

\section{Methods}

\section{Case study research design}

The research followed an interpretative research design (Walsham, 1993) with a single instrumental case study (Stake, 1995) of a telehealth innovation for glaucoma care in one Scottish Health Board. The interpretative approach was chosen because we focused on the context (the institutional pressures) of IT adoption and the process through which the IT adoption was shaped by this context (see Walsham, 1993). The case study research method was chosen because of its ability to provide rich and 
detailed data (Yin, 2003) on the perceptions of the various stakeholders involved in the adoption of the innovation. In depth data allows for thick descriptions of the case (Stake, 1995), in particular of the contextual setting (Yin, 2003) in which the innovation happens. Rich contextual understanding is critical to explain the institutional factors that shape the adoption of IT. Moreover, case study research design has been widely used in social sciences for both theory testing and theory development (Eisenhardt, 1989). The design thus suited our approach that blends theory development (understanding how institutional misalignments arise and their influence on the adoption of hybrid innovations) and theory testing (examining the institutional pressures that influence the adoption of hybrid innovation).

To answer our research questions, we first needed to identify the institutional factors that influenced the decision to adopt the telehealth innovation within the different adopting organizational fields, and to link these observed factors to the factors derived from existing institutional research on IT adoption (RQ1). This pattern matching technique between empirically observed and theoretical expected patterns is a common approach to support theory testing in single case study research designs (Yin, 2003). Once these patterns of institutional pressures had been identified, a detailed analysis of the conditions under which misalignments between these pressures arose (RQ2), and the pattern of strategic responses from potential adopters (RQ3) followed. This analysis involved iterative comparisons between the emerging theory and the case study data (see Eisenhardt, 1989) and served to build an understanding of (i) how misalignments emerged through demands for different types of legitimacies, and (ii) how responses to these misalignments led to conflicting organizing visions within each adopting field, and how these conflicting organizing visions ultimately shaped the decision to abandon the innovation (see Figure 5). 


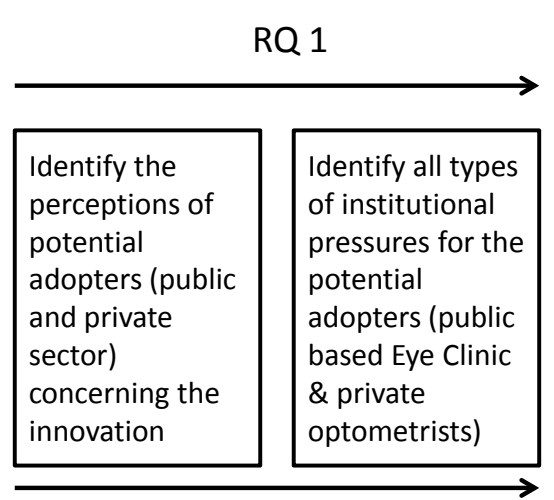

Theory testing
RQs $2 \& 3 a$

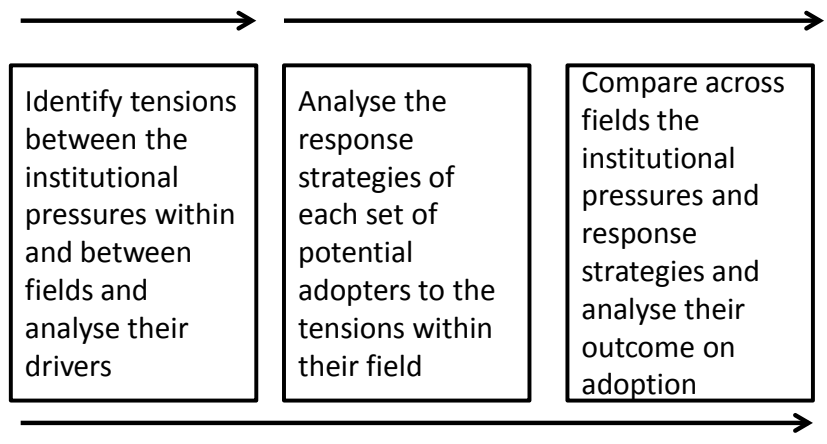

Theory building

RQ1: What are the institutional factors that influence the adoption of boundary spanning IT innovation by individual organisations?

RQ2: How do institutional misalignments arise within (RQ2a) and between (RQ2b) organizational fields involved in the adoption of boundary spanning innovations?

RQ3: How do institutional misalignments within (RQ3a) and between (RQ3b) organizational fields influence the adoption of boundary spanning innovations within individual organizations?

Figure 5: Research design

The selection of the case study matched the intensity criterion (Miles and Huberman, 1998). The health sector is widely documented as being highly institutionalised (see Currie, 2012; Scott et al., 2000) and it was therefore likely that institutional pressures in the sector would be more intense in shaping innovation adoption than in other organizational fields. Cases where the intensity of the phenomena is extreme are well suited to theory testing (RQ1) in single case study designs (Yin, 2003).

Although Eisenhardt (1989) recommends multiple case studies for theory development, single case study research design has also been used extensively for theory building (RQ2\&3) in institutional information systems literature (see for example Butler, 2003; Cho and Mathiassen, 2007; Jensen et al., 2009), and is widely considered to be a legitimate endeavour in qualitative interpretative research in information systems (Klein and Myers, 1999; Lee and Baskerville, 2003). A common criticism of single case study research for theory building is its inability to provide generalisable findings in the positivistic sense. In qualitative research, however, the development of a thick description of a context is more important than the identification of a large representative sample. Thick description enables the development of theories to explain the behaviour and actions that are deeply rooted in the context of the particular case study (Lee and Baskerville, 2003). By providing a 
thick description of the adoption context our study enables comparisons with other settings engaged in the adoption of boundary spanning innovation in contested environments, permitting naturalistic generalisation (Stake, 1995), in which the findings from a single case study can be applied to understand other innovations occurring in similar contexts (Schofield, 2002).

\section{Research setting}

The case study involved the adoption of a telehealth innovation to support glaucoma care in one Health Board in Scotland, UK. The innovation was designed to connect the public hospital-based Eye Clinic with the private sector optometry practices. Glaucoma is a degenerative eye condition involving damage to the optic nerve. It is the second most common cause of blindness in the world, and is more prevalent in people over seventy-five (Quigley, 1996). Generally the condition progresses slowly (stable glaucoma), but in acute cases the disease progresses rapidly (ibid.). Once diagnosed with glaucoma, patients require regular checks to monitor the progress of the disease. The frequency of checks varies depending on the nature of patient's condition (stable or more acute) and is generally every six months for stable glaucoma patients (NICE, 2009). Until the pilot intervention described in the study, the checks were carried out at Eye Clinics located in two public hospitals within the Health Board. The telehealth pilot involved moving the monitoring of one hundred patients with stable glaucoma from the Eye Clinic to six private local optometry practices over a sixmonth period in $\mathbf{2 0 0 9}$ for one, and in some cases two, glaucoma appointments. The optometry practices carried out routine checks for patients with slowly progressing (stable) glaucoma and, using the existing NHS IT network, emailed the results of these checks to the consultant in the Eye Clinic. The six optometry practices that agreed to take part in the telehealth pilot all had the necessary equipment to conduct the tests and transmit the results. The patients were selected randomly from patients with stable glaucoma who required appointments at the Clinic during the six months when the pilot took place. All but one of the hundred patients selected consented to being seen by optometry practices close to their homes. 
The telehealth pilot was part of a wider effort to encourage boundary spanning innovation in healthcare in the UK. For example, the England and Wales Health and Social Care Act 2012 specifically enshrines a 'fair-playing field' principle, where patients have the right to choose services which best meet their needs, including services delivered by charitable and independent providers (Department of Health, 2010a; 2012). Similarly, one of the principles enshrined in the recent NHS Constitution in Britain is that the NHS will work across organizational boundaries with other organizations from the public, private and voluntary sector to deliver health care (Department of Health, 2013).

\section{Research design: data collection and analysis}

The research was designed in two phases over 6 months (see Table 2). In Phase 1 we collected data on the institutional factors influencing the stakeholders' perceptions of the innovation. This involved extensive interviews, prior to adoption, with stakeholders involved in the design, development and adoption of the telehealth innovation. Phase 2 assessed the outcome of the innovation six months after the introduction of the telehealth system and involved follow-up interviews with key respondents from both sectors. Phase 1 provided the main source of data for conducting the analysis, while the data from Phase 2 served to assess the outcome of the innovation.

\begin{tabular}{|l|l|l|}
\hline Research phase & Research goal & Data collection instrument \\
\hline $\begin{array}{l}\text { Phase 1, prior to } \\
\text { adoption }\end{array}$ & $\begin{array}{l}\text { To collect in depth data } \\
\text { about the institutional } \\
\text { contexts, the nature of } \\
\text { the IT innovation, and } \\
\text { the perceptions of } \\
\text { future users about the IT } \\
\text { innovation. }\end{array}$ & $\begin{array}{l}\text { Sixteen in depth semi-structures } \\
\text { interviews with future users, eight } \\
\text { within the public based Eye clinic, } \\
\text { and eight within the private } \\
\text { optometrists practices } \\
\text { Publicly available information about } \\
\text { the context e.g. glaucoma } \\
\text { guidelines for the Scottish NHS, } \\
\text { optometrists contracts }\end{array}$ \\
\hline $\begin{array}{l}\text { Phase 2, after 6 } \\
\text { months following } \\
\text { the adoption of } \\
\text { the innovation }\end{array}$ & $\begin{array}{l}\text { To collect data about the } \\
\text { outcome of the IT } \\
\text { innovation and the } \\
\text { perceptions of the users }\end{array}$ & $\begin{array}{l}\text { Four interviews with users, one } \\
\text { within the clinic, and three with } \\
\text { optometrists } \\
\text { Patients questionnaire }\end{array}$ \\
\hline
\end{tabular}




\begin{tabular}{|l|l|l|}
\hline & $\begin{array}{l}\text { following the adoption } \\
\text { and use of the IT } \\
\text { innovation. }\end{array}$
\end{tabular}

Table 2. Phases in research design

The respondents (see Table 3 for details of the interviewees) were selected based on their involvement with the telehealth innovation (intense), and their role in the IT innovation (users/professionals and managers/administrators). At the Eye Clinic we interviewed the only ophthalmologist consultant who was glaucoma specialist, run the majority of (complex) glaucoma clinics and therefore used the pilot system. We also interviewed the only specialist registrar (junior doctor) that was working at the time with the ophthalmologist in the glaucoma clinics, and the glaucoma specialist nurse who was running the (stable) glaucoma clinic and who was therefore directly affected by the innovation. One technician and one receptionist were selected at the recommendation of the glaucoma specialist consultant as also being heavily involved in running glaucoma clinics. The senior nurse and clinical nurse leader were selected due to the nature of their job roles that involved overseeing the clinic services and nursing staff and served to assess the wider implications of the innovation for managing the clinic. Although there was a potential bias risk in the selecting interviewees based on the recommendations of the glaucoma ophthalmologist primarily for the technician and receptionist, in practice the respondents included most of the clinical staff who worked regularly in the glaucoma clinics and were therefore likely to be involved with the telehealth innovation. On the optometrist side, we talked with all optometrists involved in using the innovation from the six participating practices. In three of these practices the optometrists also doubled as managers and practice owners. To differentiate the administrative perspective from the professional one we also talked to one of the manager optometrists in one of the larger participating optometry practices who was not directly involved in using the glaucoma telehealth innovation, but who was responsible for managing the practice. We also interviewed the lead optometrist who represented the optometrists' views on the regional NHS board in order to better understand the optometrists' operating context. 


\begin{tabular}{|c|c|c|}
\hline Group & Job description & Job role \\
\hline \multirow[t]{8}{*}{$\begin{array}{l}\text { Eye Clinic } \\
\text { staff }(\mathrm{C} 1-8)\end{array}$} & Consultant & $\begin{array}{l}\text { Runs two glaucoma clinics per week. Deals } \\
\text { primarily with complex cases. The only } \\
\text { glaucoma specialist ophthalmologist in the } \\
\text { clinic, and the only consultant to be involved } \\
\text { with the innovation }\end{array}$ \\
\hline & Specialist Registrar & $\begin{array}{l}\text { Works with the consultant on the glaucoma } \\
\text { clinics. Sees stable and complex glaucoma } \\
\text { cases }\end{array}$ \\
\hline & Specialist Nurse & $\begin{array}{l}\text { Runs one glaucoma clinic per week. Sees } \\
\text { stable glaucoma cases }\end{array}$ \\
\hline & Senior Nurse & Coordinates nursing services in the Eye Clinics \\
\hline & $\begin{array}{l}\text { Clinical Nurse } \\
\text { Leader }\end{array}$ & $\begin{array}{l}\text { Manages the nursing staff in the Eye Clinic. } \\
\text { Budget holder for the eye clinic services }\end{array}$ \\
\hline & $\begin{array}{l}\text { Clinical Director of } \\
\text { Neurovascular Unit }\end{array}$ & $\begin{array}{l}\text { Line manager for clinic medical staff. } \\
\text { Operations manager for the doctors }\end{array}$ \\
\hline & Technician & $\begin{array}{l}\text { Operates the visual fields machine (a key } \\
\text { component of the glaucoma test) }\end{array}$ \\
\hline & Receptionist & $\begin{array}{l}\text { Co-ordinates the clinics appointments and } \\
\text { oversees patient arrivals and paperwork. }\end{array}$ \\
\hline \multirow{4}{*}{$\begin{array}{l}\text { Community } \\
\text { opticians } \\
(01-8)\end{array}$} & $\begin{array}{l}3 \times \text { independent } \\
\text { optometrists }\end{array}$ & $\begin{array}{l}\text { Are all owners of practices and practicing } \\
\text { optometrists }\end{array}$ \\
\hline & $\begin{array}{l}\text { Lead optometrist in } \\
\text { NHS Region }\end{array}$ & $\begin{array}{l}\text { Oversees the future direction of optometrist } \\
\text { practices in NHS Region. Also acts as advisor to } \\
\text { optometrists }\end{array}$ \\
\hline & Manager & $\begin{array}{l}\text { Manager of large practice and optometrist, } \\
\text { travelling around different sites }\end{array}$ \\
\hline & $\begin{array}{l}3 \times \text { employed } \\
\text { optometrists }\end{array}$ & Optometrists employed in larger practices \\
\hline
\end{tabular}

Table 3. Description of interviewees and their roles

Semi-structured interviews were carried out using an interview guide (Patton, 1980), which ensured consistency in the structure of the interviews while enabling flexibility in the questions. Interviewees were asked about their views of the current service and their perceptions and expectations of the proposed telehealth innovation. The interviews were conducted by the research team and lasted between thirty and ninety minutes. All interviews were recorded and transcribed.

Data analysis started as soon as the first interview took place and progressed gradually through iterations between coding, looking for links between codes and seeking 
theoretical relationships, searching for patterns into the data, writing narratives and revising the literature (see Figure 6).

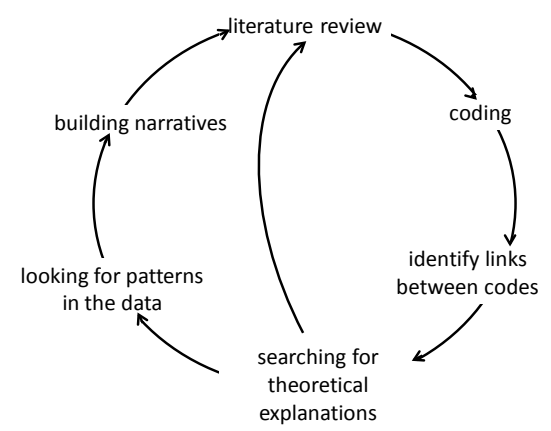

Figure 6. Iterations through data analysis

Two researchers were involved in the early stages of coding, when the initial list of codes was defined and then applied to the data. Following agreement on the initial list of codes, both researchers proceeded to code the entire set of interviews independently, with regular meetings to discuss progress. Any disagreements were reconciled gradually during this early coding phase. Once the first phase of coding finished, another researcher joined the analysis team and the analysis progressed towards identifying links between the codes, and searching for theoretical explanations. All revisions in codes at this stage followed discussions and agreement between the researchers involved in the analysis.

NVivo, a qualitative analysis software, was used to store the interviews and other documentation, and served primarily to support the initial coding of the interviews. Most of the analysis process, for example the data displays that supported the analysis process, including matrices, causal maps and process flows were done outside NVivo. The primary reason behind this decision was the relatively smaller quantity of data, which was manageable outside the software, and the different level of NVivo skills sets within the research team at the time.

An initial list of codes was developed prior to data collection. This initial list of codes was informed by the information systems and institutional literature, and included 
generic codes referring to the context of adoption such as the current process for dealing with glaucoma patients, the perceptions of the benefits and downsides associated with the proposed innovation for the different stakeholders (patients, Clinic staff and optometrists), and institutional pressures (coercive, mimetic and normative). The rationale for this coding was to explore how institutional pressures influenced the perceptions of the various stakeholders in the innovation. This list of codes was refined as data collection and coding progressed. For example, improvement in clinic capacity emerged as a key benefit during the interviews and was added to the list. Once the initial coding of the interviews was complete, data displays, including causal maps, process flows and matrices were used to further refine the data and to develop links between the different concepts and to identify emerging theoretical explanations (Miles and Huberman, 1994). Using matrices to compare the innovation perceived benefits across the Eye Clinic and the optometrist practices served to identify links between the perceptions of the innovation and the managerial and technical legitimacies within the two fields. Mapping the causal links between institutional pressures (e.g. NHS coercive pressures for reducing waiting times and normative pressures for maintaining the standard of care), strategic responses (e.g. compromising between different pressures by developing a telehealth solution for stable glaucoma patients to improve capacity while providing convenience to patients), and expectations for the organizational application of the IT innovation (e.g. wide spread deployment of telehealth system to cover most stable glaucoma patients) allowed us to build a theoretical explanation for the development of organizing visions as emerging from specific strategic responses to conflicting institutional pressures. These interpretations were refined against the literature review. For example, the concepts of managerial and technical legitimacy (Ruef and Scott, 1998) and of organizing vision (Swanson and Ramiller, 2004) emerged at a later stage in the data analysis following iterations back to the literature review to explain the misalignments between institutional pressures within the two fields, and respectively for the different interpretations of IT application developed by the two fields. 
As the links between concepts and the emerging theoretical explanations were gradually refined, patterns began to emerge that converged into tentative conclusions. For example, for both sets of actors institutional pressures could be grouped according to the type of legitimacies, suggesting that institutional misalignments emerge from seeking different types of legitimacies. These tentative conclusions provided the input into the case narratives that were developed to verify that the interpretation derived from the causal maps and matrices were plausible (see Miles and Huberman, 1994). Two sets of narratives were built, one to explain institutional misalignments and the strategic responses within each organizational field (pg 21), and one to explain institutional misalignments and their outcome on shaping conflicting visions of innovation across the two fields (pg 28). These narratives are discussed in the next section.

\section{Results and Discussion}

This section examines the institutional forces (RQ1), the misalignments between these forces and the responses of organizational actors in shaping the IT innovation adoption within (RQ2) and between (RQ3) organizational fields. We conclude the section by summarising the results from our analysis in a conceptual framework that examines the role of institutional environment in shaping the adoption of boundary spanning IT innovations.

\section{Institutional pressures, misalignments and within field outcomes for IT innovation}

In both fields, we observed the influence of a conflicting set of institutional pressures, driven by divergent demands for managerial and technical legitimacies and resolved through compromise strategies. The compromise response strategy generated a particular set of expectations concerning the application of the IT innovation within each field.

\section{Public sector}

Three institutional pressures ([1], [2] and [3] in Figure 7) framed the intention to adopt the innovation within the public-sector Eye Clinic. 


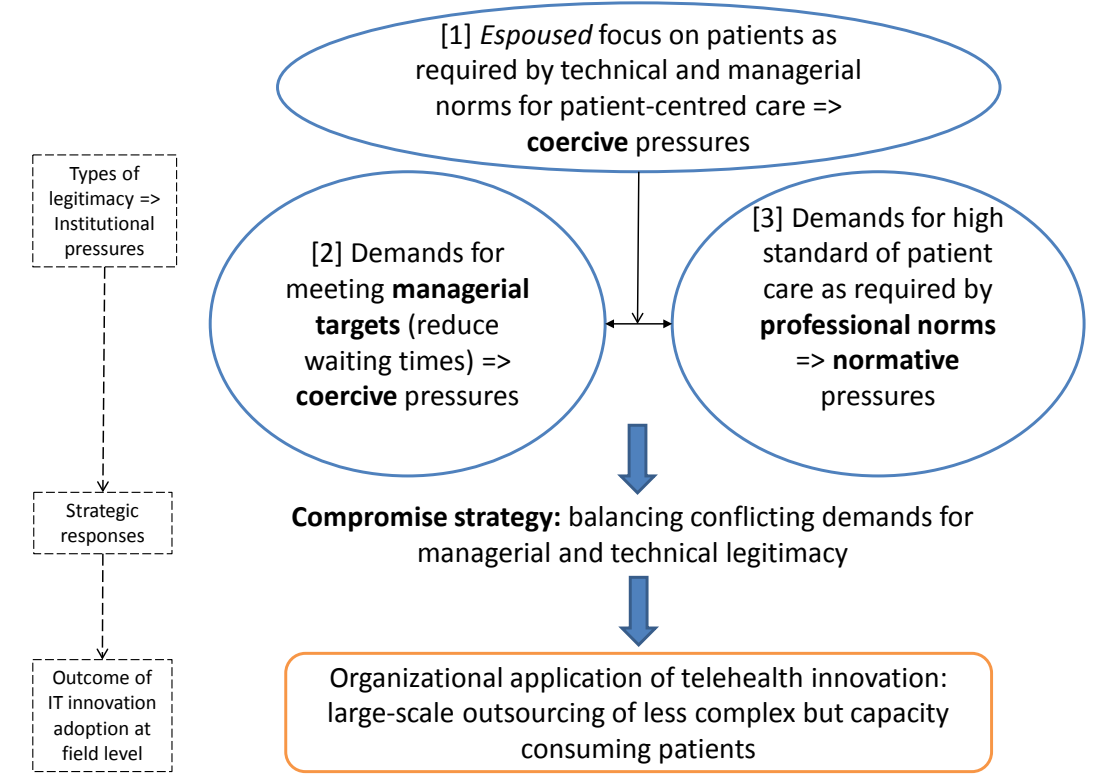

Figure 7. Institutional forces shaping the intention to adopt within the Eye Clinic

[1] First, the Clinic staff justified the innovation as benefiting patients, suggesting that coercive pressures for increased patient convenience and quality of care drove the innovation (Table 4, Quote H1). For example, respondents emphasised that patients would receive care closer to their homes $(\mathrm{H} 2)$, that they would be seen within a less stressful environment than the hospital (H3), and that the quality of care would improve for both stable $(\mathrm{H} 4)$ and complex glaucoma patients $(\mathrm{H} 5)$. This focus on patients was consistent with both managerial norms defining the performance targets for improving quality, safety and 'the patient experience' (managerial legitimacy); and with technical norms of professional excellence and work procedures (technical legitimacy) within the public health sector. For example, a "patient-centred care" agenda has been at the heart of health policies and reforms of successive UK governments, resulting in the implementation of measurements, target-setting, and the use of increased accountability and performance management systems within the NHS (Department of Health, 2010a; 2013; King's Fund 2011). Similarly, a focus on patient care delivered in partnerships with patients is at the heart of the UK medical profession (General Medical Council, 2013), while the professional standards governing the quality of care for glaucoma and endorsed by both ophthalmologists and ophthalmic nurses professional associations in the UK emphasise a positive 
experience for the patient in a caring and safe environment (NICE, 2011). This emphasis on patients' care and convenience in justifying the innovation was evidence of a coercive pressure to explain all initiatives as 'patient-focused' in order to comply with the overall NHS strategy of 'patient-centredness', fulfilling both the professional and managerial expectations for desirable and appropriate action within the NHS.

[2] Second the coercive pressure to meet government targets to reduce waiting times was another key driver for the Clinic to support the innovation. The Clinic suffered from severe capacity shortages that affected its ability to accommodate patients during appointments, and to see new patients within the timescales recommended by government targets (H6). With the number of elderly people in the UK growing, it was expected that the capacity problems and associated difficulties in meeting government targets would become more acute in the future (H7). The assumption was that if local optometrists could see stable glaucoma patients, the number of patients seen in the Clinic could be reduced, hence improving capacity. Adoption was thus largely driven by the need to comply with managerial norms for meeting the efficiency targets laid down by governmental bodies regulating the NHS (Department of Health, 2010b) by reducing the waiting times for Clinic appointments.

[3] Finally, normative pressures to maintain quality of care and allow for professional skills development were also mentioned by respondents as significant drivers for the innovation. By alleviating the capacity problems within the clinic, the innovation was perceived to lead to lighter staff workloads which would allow more time for staff training, to reduce job stress for nurses, and to increase the time spent per patient, thus improving both the quality of care and professional skills development (H8). A focus on skills development and an emphasis on patient care are consistent with expectations developed during professional training and with normative work procedures and quality assurance mechanisms (NICE, 2011; Royal College of Ophthalmologists, 2011). The demands for technical legitimacy thus manifested as normative pressures that justified the adoption of the telehealth innovation. 
The telehealth innovation was thus an attempt by the Clinic staff to respond to a combination of [1] coercive pressures to improve patients experience; [2] coercive pressures to satisfy managerial demands to meet government targets; and [3] normative pressures to maintain the standard of care. Improving patients experience fulfilled demands for both managerial and technical legitimacy through patientcentred care. In contrast, the pressure to meet government mandated targets to see more patients while dealing with diminishing physical capacity was driven by the need for managerial legitimacy and was in conflict with the normative requirements for technical legitimacy within the clinical profession. These normative demands required clinical staff to spend a set amount of time with each patient during appointments, and to allow time within their schedule for professional development, thus adding to capacity problems. The telehealth system was thus seen by the Clinic staff as a means of resolving this institutional misalignment through a compromise strategy (Oliver, 1991): the innovation would balance the different demands by outsourcing the care of stable glaucoma patients to trained optometrists. This would release clinic time to improve care for patients with complex and acute glaucoma who were seen as having more clinical requirements than stable glaucoma patients. It was also anticipated that optometrists could provide the same standard of care to stable glaucoma patients in a setting that was arguably more convenient for the patients. This compromise strategy thus led to a particular vision of the application of the telehealth system within the Clinic (see Swanson and Ramiller, 2004) who envisaged the innovation to accommodate large-scale outsourcing of less complex but capacity consuming patients. This organizing vision for large scale deployment was used by the innovator actors within the public sector to legitimise the innovation and rally support within the Clinic by emphasising the ability of the innovation to alleviate capacity problems and improve standards of care while providing greater convenience to patients.

\section{Private sector optometry practices}

Three institutional pressures ([1], [2] and [3] in Figure 8) framed the intention to adopt the innovation within the private based optometrist practices. In the UK, communitybased optometrists operate as private businesses and therefore need to make a profit. 
Much of this profit comes from dispensing glasses and contact lenses to patients, not from standard eye tests or from monitoring patients with specific conditions. The local optometrists included two distinct stakeholder perspectives: the optometrists in their role as healthcare professionals employed within a practice, and practices as businesses, sometimes run by the owner-optometrist and sometimes by employed professional managers.

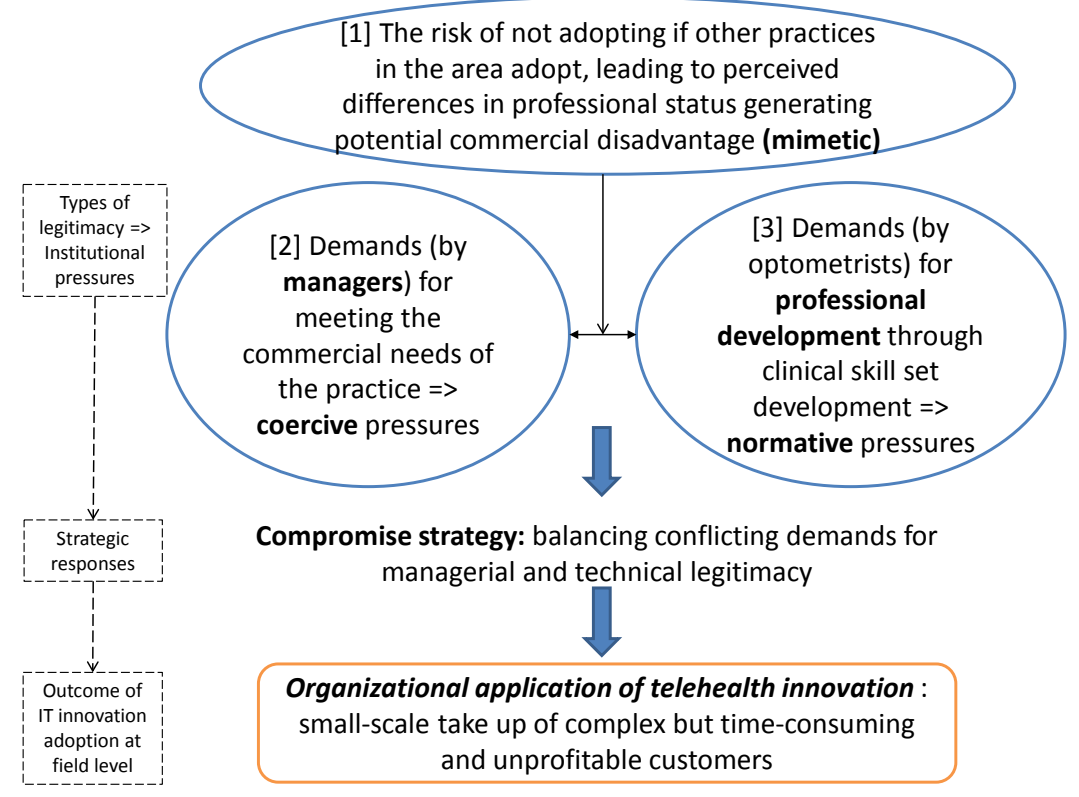

Figure 8. Institutional forces shaping the intention to adopt within the optometrists practices

[1] First, mimetic pressures played a minor role in shaping the innovation. The potential uptake and outcome of the innovation was uncertain, so practices felt some pressure to copy early adopter behaviour. Some of the practices expressed concerns that if they were not involved early, patients would somehow see them as being less capable, offering regular customers an inferior service compared to those practices involved with the innovation. The benefits for the businesses of adopting the innovation, however, were generally perceived to be small, as it was thought unlikely that the innovation would attract customers to the practice through transforming glaucoma patients into paying (and therefore profitable) customers. The concern for improving customer service and achieving competitive differentiation in the market a form of managerial legitimacy - played only a minor role in persuading practices to 
mimic the actions of lead users. Instead, the perceived business benefits were more often linked to the optometrists' professional development, and thus to technical legitimacy. Some respondents mentioned that customers might view the practices involved in glaucoma monitoring as having a higher level of clinical skills than nonparticipating competitors. They hoped that this improved perception of individual optometrists professional skills might then translate into the practice attracting more customers (L1). Mimetic pressures were therefore linked to the need to achieve the level of professional clinical skills expected by customers as being attained by early adopters of the innovation. The mimetic pressure experienced by private optometry practices thus reflected a combination of demands for both managerial and technical legitimacy, with the latter tending to dominate.

[2] Second, coercive pressures linked to profitability expectations for a private practice shaped the telehealth adoption by optometrists. While optometrists were keen to take on a few glaucoma patients as part of the pilot, they all expressed reservations about the general impact on practice profitability of seeing large numbers of patients. Respondents emphasised that the payment from the Clinic for monitoring glaucoma patients in the telehealth pilot barely covered the costs of the session (L2), and that seeing glaucoma patients carried an opportunity cost. Moreover, optometrists considered stable glaucoma monitoring as more complex (L3), and thus more timeconsuming and costly than the services typically provided by optometry practices. Both owners and employed practice optometrists emphasised that, to remain commercially viable, they could see only a limited number of glaucoma patients (L6, L7 and L8). Any outsourcing of patient care from the Clinic to optometry practices would be therefore limited by the requirement of practices to meet profitability expectations ( $\mathrm{L} 4$ and $\mathrm{L} 5$ ). This coercive pressure to meet the managerial and wider organizational (in the case of the larger practices) expectations of profitability emerged as a significant constraint in shaping the approach to the innovation in the private sector. 
[3] Finally, the key pressure driving telehealth adoption in the private sector was normative: all of the optometrists interviewed saw themselves as part of a profession dealing with patients, and not solely as business managers dealing with clients. As such, they felt they would gain professional satisfaction by getting involved in monitoring glaucoma patients (L9). Both practice owners (L10 and L11) and employed optometrists (L12) argued that dealing with glaucoma patients on a regular basis, being more involved with treatment, and working closely with clinicians would help build their expertise and professional skills. For example, one optometrist explained that she was keen to be involved because she did not like to "miss out on anything", particularly developments that might drive the profession forward (L13). In general there was also a feeling that increased job variety fitted with the optometrists' own career aspirations and their aspirations as professionals (L14). This technical legitimacy-driven focus on clinical skills development is consistent with the normative requirements prescribed for the profession by the optometrists' professional body in the UK (College of Optometrists, 2012).

The adoption of the innovation was thus an attempt by the optometrist practices to respond to a combination of [1] mimetic pressures to follow early adopter practices; [2] coercive pressures to meet the commercial needs of the practice; and [3] normative pressures to improve the level of professional skills. The demands for both technical and, to a lesser extent, managerial legitimacies to achieve differentiation in the market were met by mimicking the actions of those practices that were seen to be early adopters. In contrast, coercive and normative pressures exhibited a significant misalignment because of the different demands for managerial and technical legitimacy. Managerial legitimacy emphasised the need to engage with paying customers to maintain profitability levels, while technical legitimacy resulted in optometrists taking on non-profit making patients in order to engage with the Clinic and develop clinical skills. These tensions were evident in the language used by respondents: while optometrists talked about 'patients' in relation to the development of clinical skills, they referred to 'customers' when making a distinction between profitable customers who bought glasses, and non-profitable customers, 
such as glaucoma patients. The misalignment was resolved through a compromise strategy (Oliver, 1996): coercive and normative pressures were balanced by each practice taking only a small number of patients (typically two or three) per month. Seeing a small number of patients maintained a practice's profitability target expectations, while also enabling optometrists to develop their clinical skills through delivering glaucoma care. The compromise strategy led to a vision of the telehealth innovation that was to be applied within optometry practices (see Swanson and Ramiller, 2004) to support small scale outsourcing of glaucoma care. This organizing vision of small scale deployment allowed optometrists to legitimise the innovation within their own field and to mobilise support from both managers and professional optometrists by emphasising the ability of the innovation to develop clinical skills and to support differentiation, while having only a marginal impact of profitability margins.

\section{Institutional pressures, misalignments and across field outcomes for IT innovation}

We found that institutional misalignments arose as a result of diverse demands for technical and managerial legitimacies within and between fields. We also found that within field misalignments were amplified as tensions arose between the two fields. These misalignments compounded the differences between the organizing visions of the IT innovation developed within each field. The inability to reconcile these visions into a cohesive approach to telehealth deployment across the public and private sectors ultimately led to the abandonment of the innovation.

After six months, the pilot was stopped and the telehealth system abandoned. Followup interviews in Phase 2 found that optometrists experienced only minor technical difficulties transmitting data to the Clinic. This was associated with poor connectivity and/or the time involved in logging onto the system to send information. No other technical challenges were encountered, and all respondents emphasised the positive comments made by patients, particularly about improved convenience. The consultant ophthalmologist reported that the telehealth pilot met his original expectations in terms of the general performance of the technology, and the outcome for patients. 
The primary reason given by all parties for the failure of the innovation was that the pilot could not be scaled-up to the larger scale required to alleviate the Clinic's capacity problems. The inability to scale-up the pilot reflected the conflict between the two organizing visions within each field: the small-scale deployment to cater for a small group of clinically complex but unprofitable customers envisaged by the optometrist community versus the large scale deployment to outsource a large group of what was perceived as less complex but capacity-consuming patients by the clinical community. It became clear during Phase 1 of data collection, and was confirmed during Phase 2, that these visions could not be reconciled; the community optometrists were not able to achieve their business objectives and to see the number of patients required to have a significant impact on the capacity issues faced by the Clinic. The tensions noted in the organizing visions within each of the two fields were amplified by the institutional misalignments between the two fields. Figure 9 summaries these tensions. We can identify two sets of conflicts (grey arrows 1 and 3) and two sets of alignments (white arrows 2 and 4) that shaped the adoption decision between fields.

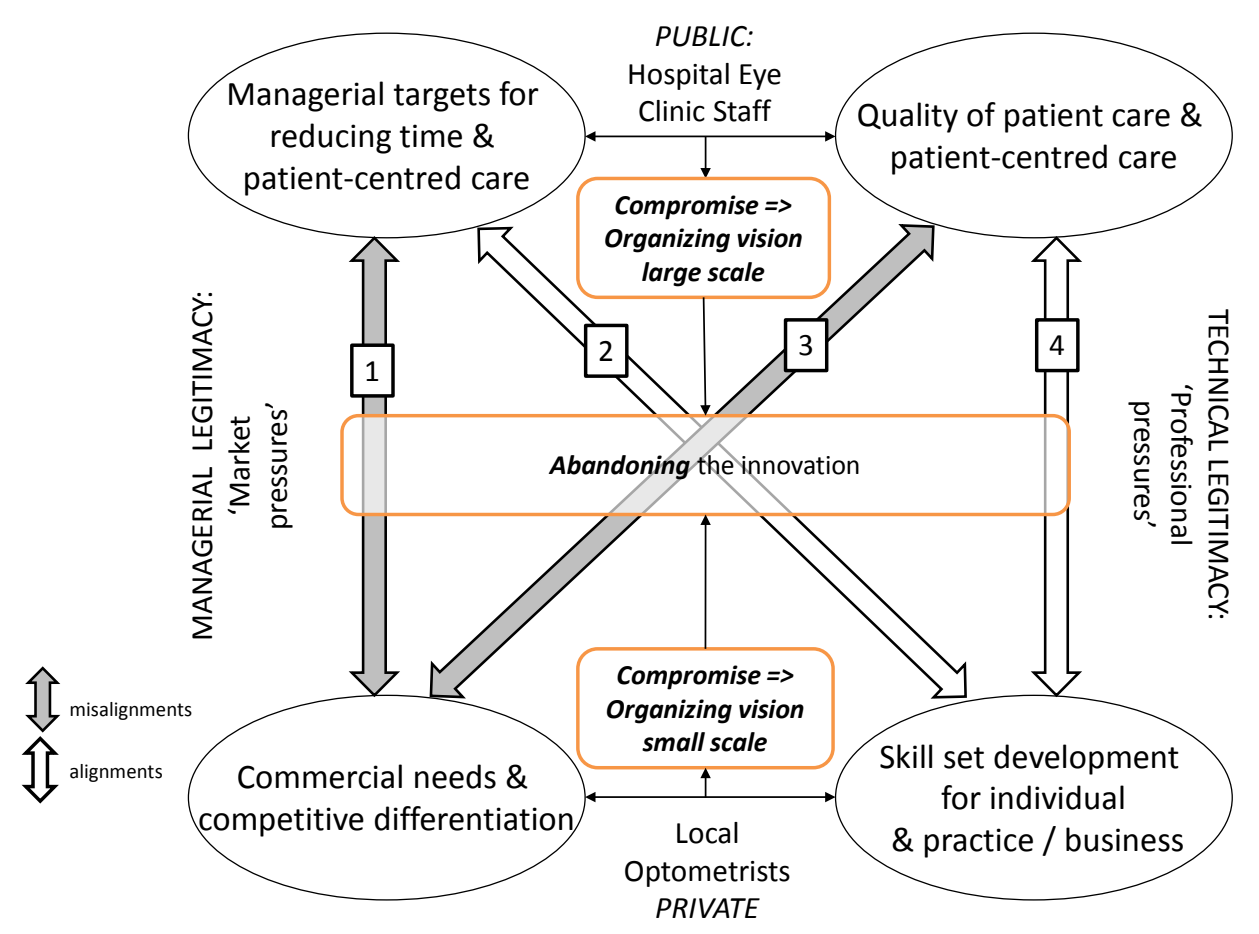


Figure 9: Tensions between the public and the private sector leading to the abandonment of the innovation

[1] In both fields, a key constraint on the application of the innovation related to the coercive pressures arising from the need to fulfil managerial expectations for economic efficiency and performance management systems. As was discussed in the previous section, in the Clinic the coercive pressure to meet government imposed targets pushed them to try to reduce capacity problems by maximising the outsourcing of patient care. In the private optometry practices the coercive pressure to meet the commercial needs of the practices pushed them to seek to minimise the provision of those services- such as routine monitoring - that were not associated with the dispensing of lenses. Each coercive pressure was very strong in its respective field, and the conflict between these pressures across the fields largely accounts for the difficulty in reconciling the field-level organizing visions for the innovation.

[2] The pressure to meet managerial targets and to reduce waiting times within the Clinic was aligned with normative pressures within the optometry practices to develop professional clinical skills. Outsourcing stable glaucoma care to trained optometrists would have allowed the Clinic to meet waiting time targets, and the optometrists to practice clinical skills and to receive on-the-job training and feedback from the ophthalmologist consultant. This strong alignment between the demands for managerial legitimacy within the clinical setting and technical legitimacy within optometrist practices explains why the innovation was initiated at all.

[3] Third, a strong misalignment existed between the normative pressures to maintain the standard of care within the Clinic and the coercive pressures to meet profitability expectations within optometry practices. Within the Clinic, the normative pressures for providing appropriate patient care meant dedicating enough time to each patient. For example, the UK professional guidelines for ophthalmic outpatient service prescribes 15-20 minutes per appointment, with the expectation that more time may be required to conduct all the necessary tests within a single appointment session 
(Royal College of Ophthalmologists, 2011). The perception among Clinic staff was that optometrists could spend more time per patient, thus enhancing quality of care (H4). This focus on technical norms of behaviour and expectations within the Clinic could also explain why none of the respondents from the Clinic considered whether the amount of reimbursement for the optometrists' services was appropriate. For local optometry practices however, the Clinic's expectations that optometrists would spend a significant amount of time on non-profitable customers conflicted with the coercive pressure to meet their own managerial norms for profitability. Different expectations of what was appropriate within each field, (focus on patient care versus making money from seeing paying customers) increased the gulf between what each set of actors saw as the appropriate application of the innovation (their organizing visions).

[4] Finally, the technical norms for engaging in patient-centred care in the Clinic, and for developing clinical skills to differentiate optometrist practices in the marketplace were aligned. In both cases, the key benefits of the innovation were seen through the eyes of patients. Like the clinicians $(\mathrm{H} 1, \mathrm{H} 2$ and $\mathrm{H} 3)$, the optometrists emphasised the benefits of the telehealth innovation to patients in terms of increased convenience arising from shorter travel times (L15), shorter waiting times during appointments (L16) and lower levels of stress and greater comfort for patients (L17). In addition, as was explained in the previous section, by engaging with glaucoma patients optometrists hoped that their practices would be perceived as differentiated in the market as a consequence of demonstrating a more advanced set of clinical skills (L1). For optometrists, however, the mimetic pressures stemming from technical demands for improving clinical skills were weak, and this alignment did not play a significant role in shaping the innovation.

Ultimately, the misalignments between the demands for legitimacy within the two sectors (arrows 1 and 3 in Figure 11) prevailed and explain the inability to agree on a coherent organizing vision between the two fields. The telehealth innovation was 
abandoned, and other ways to deliver glaucoma care remotely are currently being explored.

Boundary spanning IT adoption: legitimacy, institutional misalignments, strategic responses and organizing visions

Our analysis of the institutional pressures, the drivers for institutional misalignments and their role in shaping the adoption of boundary spanning IT innovations is summarised in the conceptual framework described in Figure 10.

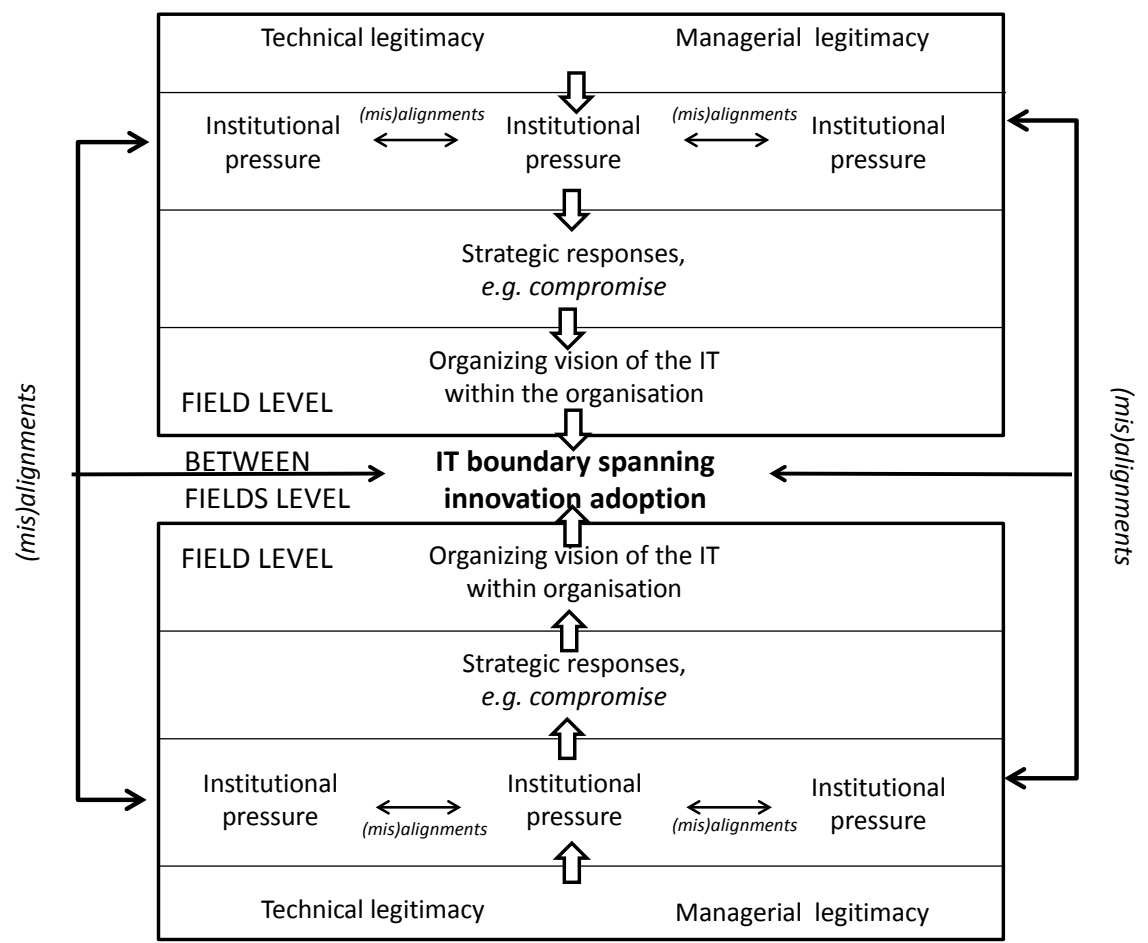

Figure 10. Conceptual framework

In line with existing research (Liu et al., 2008; Son and Bensabat, 2007; Teo et al., 2003, Tsai et al., 2013), we observed that a full range of institutional pressures: coercive, normative and to a lesser extent mimetic, influenced IT adoption within organizations (RQ1). However, in contrast to much of the existing IT innovation literature, we found that these pressures did not operate as a coherent whole, even within the same organizational field. Echoing the findings of Currie and Guah (2007) on adoption at a field level, in examining adoption at organizational level we noted that the innovation is shaped by conflicting institutional logics. Our analysis indicate that the emergence 
of institutional misalignments within and between fields is linked to different types of legitimacies (RQ2a and RQ3a). Within each field, actors responded to conflicting demands by engaging in compromise strategies that shaped their expectations about the organizational application of the innovation. Two distinct 'compromised' visions of organisational application thus emerged in each field which allowed each set of actors to legitimise the innovation and rally support for adoption within their fields (RQ2b). The degree of institutional misalignment between the fields influenced the degree to which the separately formed organizing visions could be reconciled (RQ3b). The inability to reconcile these two field-level organizing visions into a single coherent organizing vision ultimately resulted in the boundary spanning innovation being abandoned. Thus, even in a situation where compromises within fields were achieved, adoption of the boundary spanning innovation was ultimately determined by the ability (or inability) of both fields to arrive at a single, coherent, organizing vision.

\section{Conclusions}

This study makes three main contributions to information systems research. First, we contribute to research on IT innovation adoption by identifying one type of innovation, boundary spanning innovation, whose adoption cuts across different institutional fields. We argue that the hybrid nature of such innovations heightens the role that institutional misalignments play in shaping their adoption. As illustrated in our case study, institutional misalignments can often be resolved through compromise strategies that balance conflicting institutional demands within particular organizational fields. These conflicting demands tend to play a more minor role for innovations whose adoption is confined to a single organizational field. In contrast, for boundary spanning innovation, our findings indicate that the institutional misalignments between different adopting fields may amplify the conflicts at field level by reducing the ability of actors to reconcile their expectations of the organizational application of the innovation. To be successful, boundary spanning innovations need to combine diverse institutional logics in novel ways. While hybridity has been recently the subject of much research in institutional literature (e.g. Battilana and Dorado, 2010; Glynn, 2000), there has been less interest in information systems 
research to examine IT innovations that exhibit hybrid features. Generally, institutional insights into the adoption of IT innovations have been examined within the confines of particular organizational fields, such as healthcare (e.g. Cho and Mathiassen, 2007; Currie and Guah, 2007; Jensen et al., 2009), the automotive industry (Hertwig, 2012) or government (Standing et al., 2009), obscuring the role that between-field misalignments play in shaping the pattern of adoption. Our study proposes an institutionally-driven conceptual framework that identifies appropriate tools to analyse the adoption of such hybrid IT innovations.

Second, our findings augment the growing literature on why IT innovations often fail to fulfil their potential, or are poorly implemented. We have observed that while user leadership, commitment and engagement in innovation have been described as vital in information systems research (Butler, 2003), they are not sufficient conditions for adoption. Instead, in highly professionalised settings such as healthcare (Ferlie et al., 2005; Willcocks, 2004), professional orchestras (Glynn, 2000), or engineering industries (Mueller and Carter, 2007), where there are significant misalignments between the technical and managerial norms that characterise different organizational actors, the adoption of IT innovations is likely to involve conflicting norms. Our research deepens the understanding of IT adoption in hybrid environments characterised by conflicting demands for legitimacy. We have demonstrated the importance of misalignments between institutional factors within and between fields in explaining IT adoption (or the lack thereof) in contested environments.

Finally, our findings advance the current debates in IT institutional research. Most IT institutional research to-date emphasised homogeneity, and only recently has research started to consider the effect of conflicting institutional logics on organizations (Jensen et al., 2009). We have examined institutional misalignments that arise within and between organizational fields involved in innovation adoption. We have developed a framework that explains the emergence of such misalignments, and that considers a range of possible responses to these misalignments. In contrast, 
most IT research tends to focus on acquiescence responses to institutional pressures, rather than exploring other strategies for acquiring legitimacy (Mignerat and Rivard, 2009). More importantly, we have found that within each field the strategic responses to institutional misalignments shaped the actors' understanding of the organizational application of the innovation, leading to the development of different organizing visions. We thus explain the outcome of a boundary spanning innovation through the ability (or lack of it) of actors to reconcile their within-field organizing visions and to develop a coherent organizing vision of the innovation between fields. Our research thus extends the organizing vision concept developed by Swanson and Ramiller (1997) to explain how the adoption of an innovation at the organizational level is influenced by both within-field and between-field factors.

The study has a number of limitations. First, it focused primarily on the intention to adopt; the analysis of the implementation process has not been included in the analysis. Many innovations fail not because they are not sustained by users, but because their objectives are not achieved during implementation (Klein and Sorra, 1996). To understand the role that institutional (mis)alignments play in shaping innovation adoption and failure more fully, future research would need to analyse stakeholder behaviours and perceptions during implementation.

Second, we focused on a case where the actors could not reconcile their expectations during the organizational deployment of the innovation, and the innovation was abandoned. We have not examined the mechanisms through which actors can change their organizing visions by, for example, compromising their own expectations, or by adjusting the expectations of the others in order to develop a coherent vision between fields to support the adoption. Further research using a multi-case study design would enable further development and testing of the conceptual framework to include strategies for reconciling organizing visions. 


\section{References}

Battilana, J. and Dorado, S. (2010). 'Building sustainable hybrid organizations: The case of commercial microfinance organizations', Academy of Management Journal, 53(6), $1419-1440$

Benders, J., Batenburg, R. and van der Blonk, H. (2006). 'Sticking to standards: technical and other isomorphic pressures in deploying ERP-systems', Information \& Management, 43(2), 194-203

Bunduchi, R., Graham, I., Smart, A. and Williams, R. (2008). 'Homogeneity and heterogeneity in information technology private standard settings - the institutional account', Technology Analysis and Strategic Management, 20(4), 389 - 407

Butler, T. (2003). 'An institutional perspective on developing and implementing intranet- and internet- based information systems', Information Systems Journal, 13(3), 209-231

Chatterjee, D., Grewal, R. and Sambamurthy, V. (2002). 'Shaping up for e-commerce: Institutional enablers of the organizational assimilation of web technologies', MIS Quarterly, 26(2), 65 - 89.

Cho, S. and Mathiassen, L. (2007). 'The role of industry infrastructure in telehealth innovations: a multi-level analysis of a telestroke program', European Journal of Information Systems, 16(6), 738-750.

College of Optometrist (2012) Current guidance - Professional Integrity. Available at http://www.college-optometrists.org/en/professionalstandards/Ethics Guidance/recent.cfm (last accessed 29th of August, 2014).

Currie, W.L. (2004). 'The organizing vision of application service provision: a processoriented analysis', Information and Organization, 14(4), 237-267.

Currie, W.L. (2012). 'Institutional isomorphism and change: the national programme of IT - 10 years on', Journal of Information Technology, 27(3), 236-248.

Currie, W.L. and Guah, M.W. (2007). 'Conflicting institutional logics: a national programme for IT in the organisational field of healthcare', Journal of Information Technology, 22(3), 235-247 
Department of Health (2010a). Equity and excellence: Liberating the NHS. Available at: https://www.gov.uk/government/uploads/system/uploads/attachment data/file 213823/dh 117794.pdf (last accessed 29th of August, 2014).

Department of Health (2010b). The NHS Outcomes Framework 2011/12. Available at: https://www.gov.uk/government/uploads/system/uploads/attachment data/file 213789/dh 123138.pdf (last accessed 29th of August, 2014)

Department of Health, (2012). Health and Social Care Act, http://www.dh.gov.uk/health/2012/06/act-explained/ (last accessed $11^{\text {th }}$ December 2013)

Department of Health (2013). NHS Constitution for England. Available at: https://www.gov.uk/government/uploads/system/uploads/attachment data/file L170656/NHS Constitution.pdf (last accessed 29th of August, 2014)

DiMaggio, P. and Powell, W. (1983). 'The Iron Cage Revisited: Institutional Isomorphism and Collective Rationality in Organizational Fields', American Sociological Review, 48(2), pp. $147-160$

Ferlie, E., Fitzgerald, L., Wood, M. and Hawkins, C. (2005). 'The nonspread of innovations: The mediating role of professionals', The Academy of Management Journal, 48(1), 117-134.

Glynn, M. (2000). 'When cymbals become symbols: Conflict over organizational identity within a symphony orchestra', Organizational Science, 11(3), 285-298.

General Medical Council. (2013). Good medical practice. Available at:

http://www.gmc-

uk.org/guidance/good_medical_practice/professionalism in action.asp accessed 29th August 2014).

Gosain, S. (2004). 'Enterprise information systems as objects and carriers of institutional forces: The new iron cage?', Journal of the Association for Information Systems, 5(4), 151-182.

Hertwig, M. (2012). 'Institutional effects in the adoption of e-business-technology. Evidence from the German automotive supplier industry', Information and Organization, 22(4), 252-272. 
Jensen, T.B., Kjærgaard, A., and Svejvig, P. (2009) 'Using institutional theory with sensemaking theory: a case study of information system implementation in healthcare', Journal of Information Technology, 24(4), 343-353.

Klein, H.K. and Myers, M.D. (1999). 'A set of principles for conducting and evaluating interpretative field studies in information systems', MIS Quarterly, 23(1), 67-93.

King's Fund (2011) 'Improving the Quality of Care in General Practice' London: The King's Fund.

Lee, A.S. and Baskerville, R.L. (2003). 'Generalizing generalizability in information systems research', Information Systems Research, 14(3), 221-243.

Liang, H., Saraf, N., Hu, Q. and Xue, Y. (2007). 'Assimilation of enterprise systems: the effects of institutional pressures and the mediating role of top management', MIS Quarterly, 31(1), 59-87

Liu, C., Sia, C-L. and Wei, K-K. (2008). 'Adopting organizational virtualization in B2B firms: An empirical study in Singapore', Information \& Management, 45(7), 429-437 Liu, H., Ke, W., Wei, K.K., Gu, J. and Chen, H. (2010). 'The role of institutional pressures and organizational culture in the firm's intention to adopt internet-enabled supply chain management systems', Journal of Operations Management, 28(5), 375-384.

Lyytinen K. and Damsgaard, J. (2011). 'Inter-organizational information systems adoption - a configuration analysis approach', European Journal of Information Systems, 20(5), 496-509.

Marsan, J., Pare, G. and Beaudry, A. (2012). 'Adoption of open source software in organizations: A socio-cognitive perspective', Journal of Strategic Information Systems, 21(4), 257-273.

Messerschmidt, C. and Hinz, O. (2013). 'Explaining the adoption of grid computing: An integrated institutional theory and organizational capability approach', Journal of Strategic Information Systems, 22(2), 137-156.

Miles, M. and Huberman, A. (1994). Qualitative Data Analysis: An Expanded Sourcebook (2nd ed.). Thousand Oaks, CA: Sage Publications.

Mignerat, M. and Rivard, S. (2009). 'Positioning the institutional perspective in information systems research', Journal of Information Technology, 24(4), 369-391. 
Mueller, F. and Carter, C. (2007). 'We are all managers now: Managerialism and professional engineering in UK electricity utilities', Accounting, Organization and Society, 32(1-2), 181-195.

NICE (2009). ‘Glaucoma: Diagnosis and management of chronic open angle glaucoma and ocular hypertension. Quick reference guide', NHS National Institute for Health and Clinical Excellence (NICE) Clinical Guideline 85. Found at http://www.nice.org.uk/cg85 (last accessed 11th December 2013).

NICE (2011). 'Glaucoma quality standard', available at: http://www.nice.org.uk/guidance/qs7 (last accessed 29th of August, 2014).

Oliver, C. (1991). 'Strategic responses to institutional processes', Academy of Management Review, 16(1), 145-179.

The Royal College of Ophthalmologists (2012). 'Ophthalmic Services Guidance, Ophthalmic Outpatient Department', available at http://www.rcophth.ac.uk/page.asp?section=293\&sectionTitle=Ophthalmic+Servi ces+Guidance (last accessed on August, 2014).

Pache, A-C. and Santos, F. (2010). 'When world collide: the internal dynamics of organizational responses to conflicting institutional demands', Academy of Management Reviews, 35(3), 455-476.

Patton, M. (1980). Qualitative Evaluation Methods. London: Sage.

Quigley, H. (1996). 'Number of people with glaucoma worldwide' British Journal of Ophthalmology, 80(5), 389-393.

Reay, T. and Hinings, C.R. (2009). 'Managing the rivalry of competing institutional logics', Organization Studies, 30(6), 629-652.

Ruef, M. and Scott, W. (1998). 'A multidimensional model of organizational legitimacy: Hospital survival in changing institutional environments', Administrative Science Quarterly, 43(4), 877-904.

Scherer, A.G., Pallazo, G. and Seidl., D. (2013). 'Managing legitimacy in complex and heterogeneous environments: sustainable development in a globalized world', Journal of Management Studies, 50(2), 259-284.

Scott, W.R. (1987). 'The Adolescence of Institutional Theory', Administrative Science Quarterly, 32(4), 493 - 511. 
Scott, W.R., Ruef, M., Mendel., P.J. and Caronna, C.A. (2000). Institutional change and healthcare organizations, Thousand Oaks, CA: Sage Publication.

Sodero, A.C., Rabinovich, E. And Sinha, R.V. (2013). 'Drivers and outcomes of openstandard interorganizational information systems assimilation in high-technology supply chains', Journal of Operations Management, 31(6), 330-344.

Son, J-Y and Benbasat, I. (2007). 'Organizational buyers' adoption and use of B2B electronic marketplaces: efficiency- and legitimacy-oriented perspectives', Journal of Management Information Systems, 24(1), 55-99.

Standing, C., Sims, I. and Love, P. (2009). 'IT non-conformity in institutional environments: E-marketplace adoption in the government sector', Information \& Management, 46, 138-149.

Suchman, M.C. (1995). 'Legitimacy: strategic and institutional approaches', The Academy of Management Review, 20(3), 571-610.

Swanson, E.B. and Ramiller, N.C. (1997). 'The organizing vision in information systems innovation', Organization Science, 8(5), 458-474.

Swanson, E.B. and Ramiller, N.C. (2004). 'Innovating mindfully with information technology', MIS Quarterly, 28(4), 553-583.

Teo, H., Wei, K. and Benbasat, I. (2003). 'Predicting intention to adopt interorganizational linkages: An institutional perspective', MIS Quarterly, 27(1), 19 49.

Tsai, M-C., Lai, K-H. and Hsu, W-C. (2013) 'A study of the institutional forces influencing the adoption intention of RFID by suppliers', Information \& Management, 50(1), 5965.

Walsham, G. (1993). Interpreting information systems in organizations. Chichester, UK: Wiley.

WHO (2010) 'Telemedicine: Opportunities and Developments in Member States' WHO (Geneva)

found at http://www.who.int/goe/publications/goe telemedicine 2010.pdf (last accessed 11th December 2013).

Willcocks, S. (2004). 'Clinician managers and cultural context: comparison between secondary and primary care', Health Services Management Research, 17(1), 36-46. 
Yin, R. (2003). Case Study Research: Design and Methods ( $3^{\text {rd }}$ edn.). Thousand Oaks, CA: Sage.

Zimmerman, M.A. and Zeitz, G.J. (2002). 'Beyond survival: achieving new venture growth by building legitimacy', Academy of Management Review, 27(3), 414-431. 
Table 4. Summary of evidence

\begin{tabular}{|c|c|c|}
\hline Focus on ... & Explanation & Exemplary quotes \\
\hline \multicolumn{3}{|c|}{ PUBLIC SECTOR: Hospital based clinic staff } \\
\hline \multirow[t]{4}{*}{ Patients } & $\begin{array}{l}\text { Convenience of } \\
\text { being seen } \\
\text { locally }\end{array}$ & $\begin{array}{l}\text { "I think the main benefits are meant to be for the patients, because they will not need to travel. They will } \\
\text { have appointments at the time that they are told. They are going to have secondary care at a local level" } \\
(\mathrm{C} 1 \text {, Quote } \mathrm{H} 1 \text { ) }\end{array}$ \\
\hline & $\begin{array}{l}\text { Reduces travel } \\
\text { time and cost to } \\
\text { patients }\end{array}$ & $\begin{array}{l}\text { "[the main benefits include] patient travel time, parking, better service provided, better training. To be } \\
\text { honest, I think the patients would benefit most, because they wouldn't be travelling in to [Hospital City]" } \\
(\mathrm{C} 6, \text { Quote } \mathrm{H} 2)\end{array}$ \\
\hline & $\begin{array}{l}\text { Reduces patient } \\
\text { anxiety }\end{array}$ & $\begin{array}{l}\text { "you can save the patient undue anxiety that is associated with attending the clinic, and wondering "what's } \\
\text { going on with my eyes?"” (C2, Quote H3) }\end{array}$ \\
\hline & $\begin{array}{l}\text { Improve patient } \\
\text { treatment } \\
\text { compliance }\end{array}$ & $\begin{array}{l}\text { Maybe if people could just drop into their opticians, I'm not saying the opticians will be sitting there with } \\
\text { nothing to do ... but if they could access treatment or access care a little bit more easily, rather than actually } \\
\text { going through the rigours of getting an outpatient's appointment here, you could improve compliance [with } \\
\text { treatment regimens] because that is actually something that we don't do enough of here. It would help } \\
\text { promotion, the follow-up, just explain to people how important compliance is. At the moment we neither } \\
\text { have the facilities nor the time to do it." (C4, Quote } \mathrm{H} 4)\end{array}$ \\
\hline
\end{tabular}




\begin{tabular}{|c|c|c|}
\hline & $\begin{array}{l}\text { More clinic time } \\
\text { available for } \\
\text { complex cases }\end{array}$ & $\begin{array}{l}\text { "if in the clinic [we had] those more complex patients that probably can't be managed by the optometrist, } \\
\text { then I would imagine that we would reduce the numbers in the clinic. So we would have a bit more time } \\
\text { with each individual patient, which would ensure that they got a high quality of care" (C6, Quote H5) }\end{array}$ \\
\hline \multirow[t]{3}{*}{ Clinic staff } & $\begin{array}{l}\text { Improved clinic } \\
\text { capacity and } \\
\text { meeting } \\
\text { management }\end{array}$ & $\begin{array}{l}\text { "I have concerns that waiting time targets measure new patients' appointments. Because we have a partial } \\
\text { booking system, I worry sometimes that we say, 'We'll see them in six months,' but they actually disappear } \\
\text { into the ether and it could be that they are waiting longer than six months for their return appointments, } \\
\text { because we just don't have enough capacity" (C6, Quote H6). }\end{array}$ \\
\hline & $\begin{array}{l}\text { Future capacity } \\
\text { problems } \\
\text { because of aging } \\
\text { population }\end{array}$ & $\begin{array}{l}\text { "As the population get older, we're going to get more patients. Doesn't matter what we do, we're going to } \\
\text { get more patients, and if it means we can see some of these out in the community or in any way increase } \\
\text { our capacity, it's got to be good. As it [is] just now I don't think we can go much longer without the whole } \\
\text { thing collapsing around our ears because it's getting to the where point there are just too many patients" } \\
\text { (C3, Quote H7). }\end{array}$ \\
\hline & $\begin{array}{l}\text { Staff skill } \\
\text { development } \\
\text { and the provision } \\
\text { of quality of care }\end{array}$ & $\begin{array}{l}\text { "it would make things easier because I would be able to provide a better [service] and nurses would have } \\
\text { the time that they need to develop [skills], as opposed to doing their ultimate best to get all these patients } \\
\text { through the clinics with such a fast turnover They'd be able to give a better quality of care" (C5, Quote H8). }\end{array}$ \\
\hline
\end{tabular}




\begin{tabular}{|c|c|c|}
\hline \multirow[t]{4}{*}{$\begin{array}{l}\text { Optometry } \\
\text { practices }\end{array}$} & $\begin{array}{l}\text { gaining extra } \\
\text { customers } \\
\text { through } \\
\text { perceived better } \\
\text { professional } \\
\text { skills }\end{array}$ & $\begin{array}{l}\text { "I: You would get more involved with the treatment of these patients? } \\
\text { R: Yes. } \\
\text { I:Or is this in terms of professional development? } \\
\text { R: Yeah, yeah. Also it's good for the practice you know, if people get to know that you're doing this as well } \\
\text { you know, it's advertising in a way." (O1, Quote L1) }\end{array}$ \\
\hline & $\begin{array}{l}\text { Payment fee for } \\
\text { glaucoma care }\end{array}$ & $\begin{array}{l}\text { "Profitability could be an issue if [patient] numbers get excessive, but I don't think with this sort of system } \\
\text { they would be. A break-even figure for a practice is around } f 120 \text { per hour. So we're just breaking even at } \\
\text { the fees that have been agreed for this. It's not going to make the practice profitable" (O1, Quote L2) }\end{array}$ \\
\hline & $\begin{array}{l}\text { Time consuming } \\
\text { during learning } \\
\text { period \& need to } \\
\text { change }\end{array}$ & $\begin{array}{l}\text { "[the consultant] has asked me to do specific tests that are different from the tests that I would normally do } \\
\text { and it's all new to me. It's not like my normal routine. Although [the consultant] is not asking me to do } \\
\text { anything that I can't do, it's just different from what I normally do. [In time] it'll get better" (O6, Quote L3) }\end{array}$ \\
\hline & $\begin{array}{l}\text { Potential impact } \\
\text { on practice } \\
\text { profitability }\end{array}$ & $\begin{array}{l}\text { "By seeing a lot more glaucoma patients and becoming an offshoot of the hospital, we are reducing the } \\
\text { business for dispensing glasses This has certainly been raised as a concern for other areas where the hospital } \\
\text { has shifted the balance of care. Obviously in the hospital they are paid through an NHS contract salary, not } \\
\text { as a business" (O2, Quote } \mathrm{L} 4) \text {. }\end{array}$ \\
\hline
\end{tabular}




\begin{tabular}{|c|c|c|}
\hline & & $\begin{array}{l}\text { "my manager will tell you that she hates it because these are people who are not our patients, they're not } \\
\text { buying glasses, they're not making us any money whatsoever. So from a financial point of view it's very poor } \\
\text { for the practice" (06, Quote } \mathrm{L} 5) \text {. }\end{array}$ \\
\hline & $\begin{array}{l}\text { Practices could } \\
\text { take only a small } \\
\text { number of } \\
\text { patients }\end{array}$ & $\begin{array}{l}\text { "[because of the economic downturn] we are probably seeing a lot more non-prescribing patients. At the } \\
\text { moment we have room for them [so] it depends how many there are of them. If it's only one of two then } \\
\text { yes, fine, we can fit them in without too much bother" ( } \mathrm{O} 4 \text {, Quote } \mathrm{L} 6) \text {. } \\
\text { "If it was massive numbers, it would not be financially viable for us to do." (O8, } \mathrm{L} 7) \text {. } \\
\text { "It would depend a bit on the number of patients. If it was only going to be a small number of practices } \\
\text { doing it, but a large number of patients, then yes, that would have a negative impact on business and I think } \\
\text { practices would then be reluctant to take part because managers would not be making any money because } \\
\text { we would have too many patients" (O3, Quote } \mathrm{L} 8) \text {. }\end{array}$ \\
\hline Optometrist & $\begin{array}{l}\text { Professional } \\
\text { satisfaction } \\
\text { through fuller } \\
\text { use of skills set }\end{array}$ & $\begin{array}{l}\text { "It does give you a wee bit more variety in your work and also the chance to use the skills you actually } \\
\text { studied for at university. We were trained to have a look to see if there's anything that's not quite right with } \\
\text { the eyes and it's quite nice to actually get the responsibility to be the one to make sure that their glaucoma } \\
\text { is still stable" (O7, Quote L9) }\end{array}$ \\
\hline & $\begin{array}{l}\text { Development } \\
\text { and refinement } \\
\text { of skills and }\end{array}$ & $\begin{array}{l}\text { "There are a few drivers really. There's definitely the one of increasing professional skills and being involved } \\
\text { in more varied eye care work ... Certainly for me there would be professional satisfaction in improving my } \\
\text { clinical skills" (O1, Quote } \mathrm{L} 10)\end{array}$ \\
\hline
\end{tabular}




\begin{tabular}{|c|c|c|}
\hline & $\begin{array}{l}\text { enhancement of } \\
\text { profession }\end{array}$ & $\begin{array}{l}\text { "I think it's good from my point of view because we will be able to be involved more in the management } \\
\text { and treatment of these patients" (O4, Quote L11). } \\
\text { "I'm interested in any further development in any sort of shared care system. I think it's the way our } \\
\text { profession should go ... I do think it's the way that eye care should go, removing people from centrally-based } \\
\text { hospitals into the community if they can" (O1, Quote L12). } \\
\text { "I don't like to be left out of anything! That's basically it really. I am very forward thinking about optometry } \\
\text { and it's one of those things that's good for bringing us forward and get involved with these things" (O4, } \\
\text { Quote L13). }\end{array}$ \\
\hline & $\begin{array}{l}\text { Increased job } \\
\text { satisfaction } \\
\text { through variety }\end{array}$ & $\begin{array}{l}\text { "As an optometrist I like the variety ... You've got all sorts of different things that you're seeing and I'm quite } \\
\text { involved in pathology and the medical side of it. I quite like that side of it" (O6, Quote L14) }\end{array}$ \\
\hline Patients & $\begin{array}{l}\text { Being seen } \\
\text { locally, in a } \\
\text { familiar and non- } \\
\text { clinical } \\
\text { environment }\end{array}$ & $\begin{array}{l}\text { "I think there's a huge benefit ... because patients don't have to go to hospital. The service would be much } \\
\text { more localised which, for older patients is a huge issue; they want to be seen as locally as possible" (O1, } \\
\text { Quote L15). } \\
\text { "It's all done in probably an hour versus spending four or five hours [waiting] at the hospital, plus travelling } \\
\text { time" (O3, Quote L16). } \\
\text { "They're familiar with [the local village] and familiar with this practice and the staff here so they're a wee } \\
\text { bit more at ease about coming in. They're not so tense and they're not coming to see a doctor, they're }\end{array}$ \\
\hline
\end{tabular}




\begin{tabular}{|l|l|l|}
\hline & $\begin{array}{l}\text { coming to see an optician who's maybe a wee bit more human in their eyes; they're not some sort of super- } \\
\text { brain. They just feel a wee bit more relaxed" (O7, Quote L17). }\end{array}$ \\
\hline
\end{tabular}

